21.S8

\title{
Fetal Tissue Guidelines Depart from the Cadaver Donor Framework
}

\author{
Karen G. Gervais, Dorothy E. Vawter and Arthur L. Caplan \\ Center for Biomedical Ethics, University of Minnesota, Box 33 UMHC \\ 420 Delaware St. SE, Minneapolis, MN 55455, USA
}

It is widely held that human fetal tissue used in transplantation should be treated as any other human cadaver tissue. Treating the dead fetus as a cadaver is more respectful than treating it as a tissue specimen. However, despite the prevalence of references to the cadaver donor framework in several national fetal tissue guidelines, provisions that depart from this framework are frequently included. These departures provide both the fetus and the woman with respect and protection beyond that offered by the cadaver donor framework. The cadaver donor framework consists of the following:

* Next-of-kin must give explicit written consent to the use of the tissue in education, research, or therapy

* Consent disclosure may be minimal

* Next-of-kin may base consent on their own interests, preferences, and values

* Next-of-kin may designate recipients or specific use

* One next-of-kin may veto another's decision

* Users must be involved in neither the care of the deceased nor in the determination of death

* Tissue may not be bought or sold.

Additional provisions for the fetus are of two types. The first stems from the belief that electively aborted fetuses deserve a respect unnecessary for other cadavers. For example:

* Tissue may be used only for biomedical purposes /2/

* Information must be unobtainable by other means $/ 1,2$,

* An institutional ethics committee must oversee the research /1-4/.
The second type stems from the belief that the living fetus deserves special protection. The use of fetal tissue must be prevented from encouraging abortion for donation in ways considered unnecessary to prevent cadaver donation from encouraging suicide or murder. For example:

* The woman must consent to abortion before discussing donation $/ 2,4,5 /$

* The woman may not abort for purposes of donating tissue $/ 1,2 /$

* The woman may not specify how tissue is to be used /2,5/

* The woman may not designate recipient $/ 2,4,5 /$

* An intermediary should be used to transfer tissue and information between abortion provider and tissue user /2/

* Abortion providers and women should receive no inducements $/ 2,4 /$.

Additional provisions for women asked to donate tissue are of two types. The first stems from the belief that such women deserve respect that is unnecessary for next-of-kin in cadaver donation generally. For example:

* The woman's consent is necessary /1-5/

* The father cannot veto the woman's decision /2,5/

* The woman must be given all information requested $/ 1,4 /$.

The second type stems from the belief that women asked to donate fetal tissue after induced abortion deserve protection unnecessary for next-of-kin in cadaveric donation generally. For example: 
* Abortion procedures may not be modified /1-5/

* Any known risks to privacy or medical wellbeing must be disclosed $/ 5 /$.

* The woman's identity must be protected /2,5/

* Inform woman and obtain consent for HIV testing, etc. $/ 2,5 /$

* Those attending the woman must be separate from those conducting research /1-4/

* Use intermediary between abortion provider and tissue user $/ 2 /$

* Physician's interest in tissue must be disclosed $15 /$

* Woman and recipient must not communicate $13 /$.

These additional provisions in the fetal tissue guidelines suggest that the cadaver donor framework inadequately respects and protects the fetuses and women involved. The Swedish guidelines adhere most closely to the cadaver donor framework. Those of Australia and the United States' NIH Panel add moderately to this framework. Great Britain's Polkinghorne Report gives significantly greater attention to respect and protection of the fetus and the woman. Finally, the United States Congress goes furthest in respecting and protecting the woman. This analysis of fetal tissue guidelines suggests that fetal tissue donation pursuant to elective abortion raises unique ethical issues that lie outside the scope of the standard principles governing cadaver donation.

\section{REFERENCES}

1. National Health and Medical Research Council. Ethics in Medical Research Involving the Human Fetus and Human Fetal Tissue. Canberra: Australian Government Publishing Service, 1983. Reprinted in the Medical Journal of Australia, May 12, 1984, 610-20.

2. Review of the Guidance on the Research Use of Fetuses and Fetal Material [Polkinghorne Report]. London: Her Majesty's Stationery Office, 1989.

3. Swedish Society of Medicine. Guiding Principles for the Use of Fetal Tissue in Clinical Transplantation Research, 1990.

4. Consultants to the Advisory Committee to the Director National Institutes of Health. Report of the Human Fetal Tissue Transplantation Research Panel December, 1988, Volume I.

5. U.S. House of Representatives, 102D Congress, H.R. 5495, June 25, 1992; U.S. Senate, 102D Congress, S.2899, June 25, 1992. 

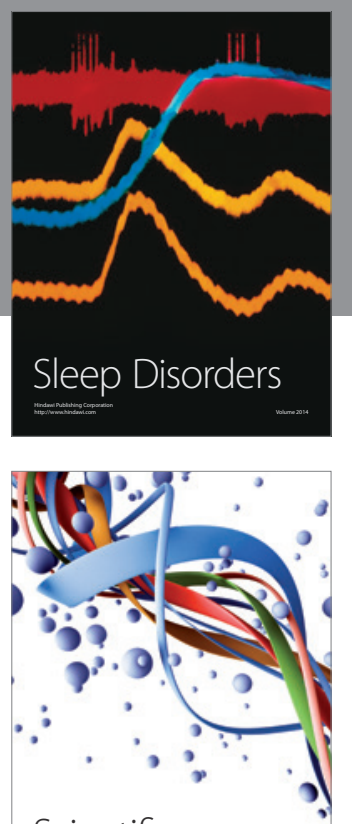

Scientifica
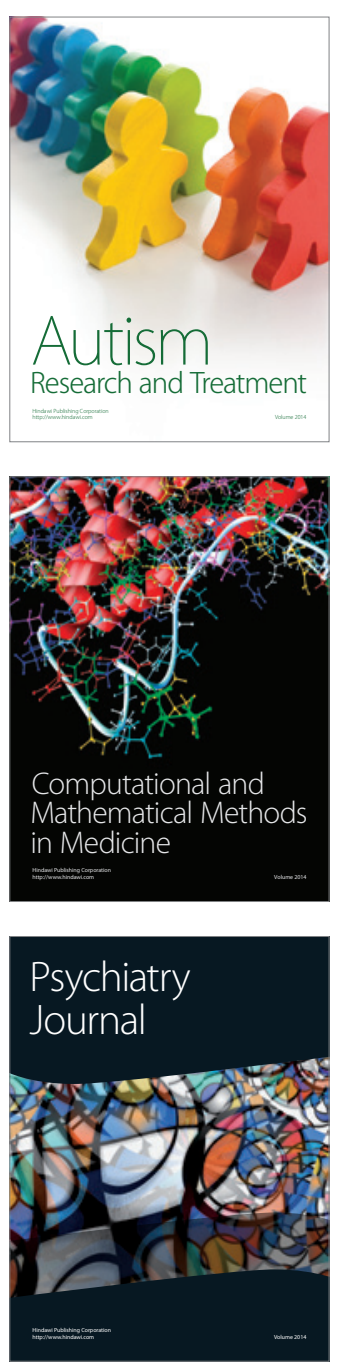
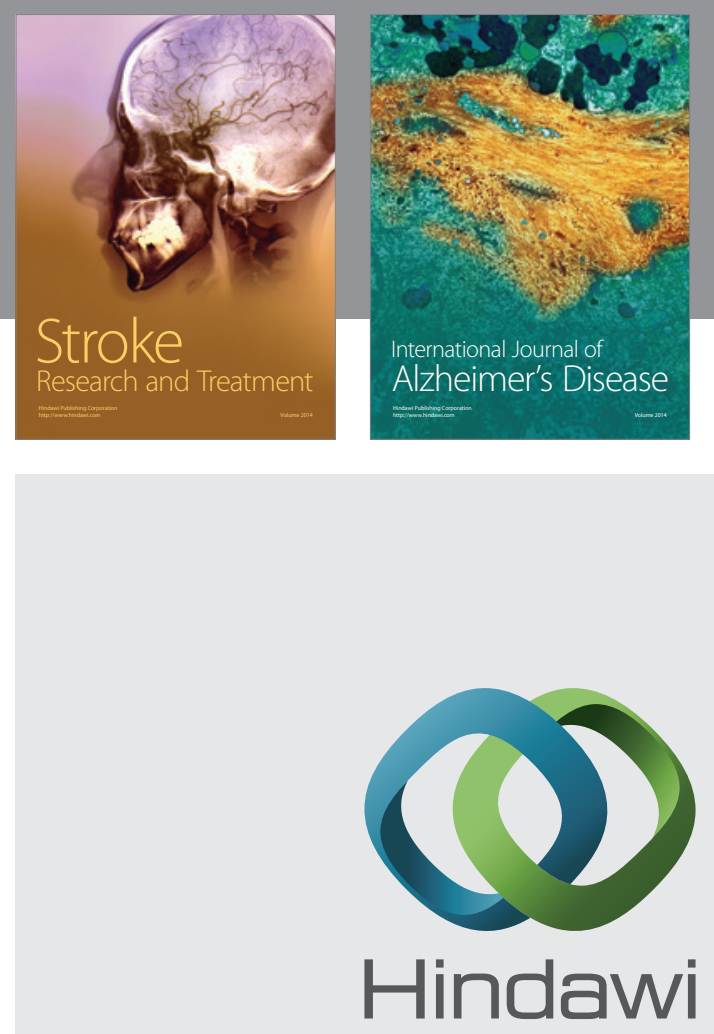

Submit your manuscripts at

http://www.hindawi.com
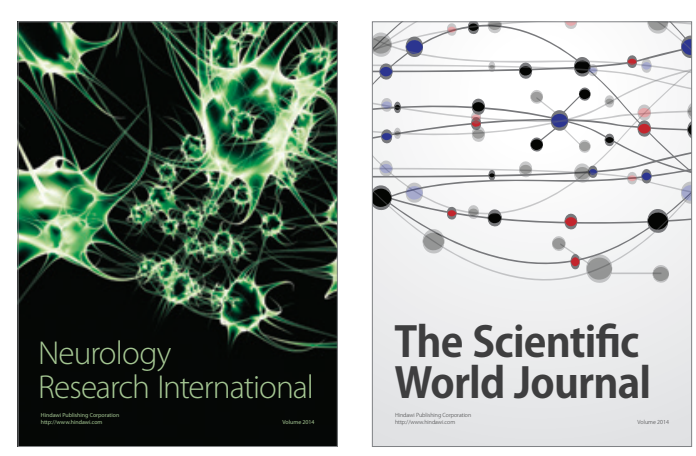

The Scientific World Journal

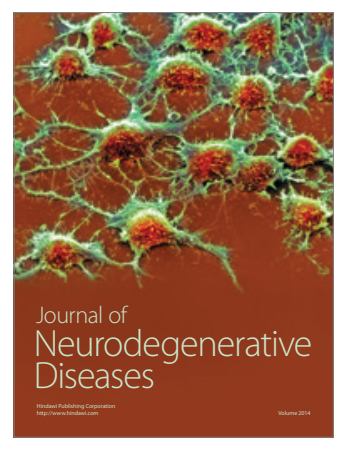

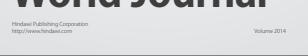

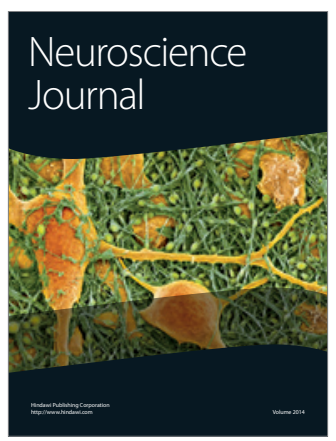

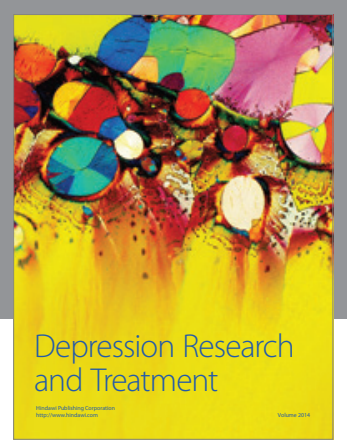
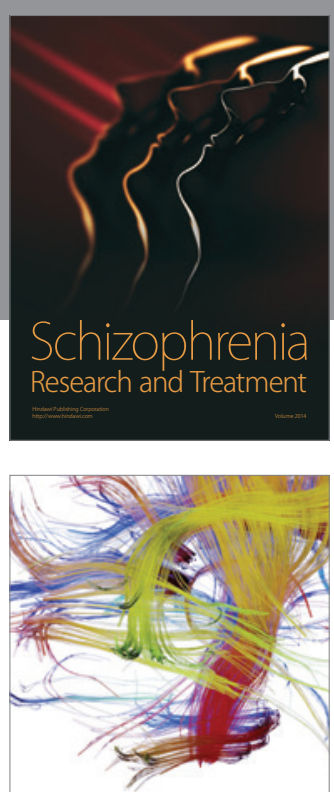

Brain Science

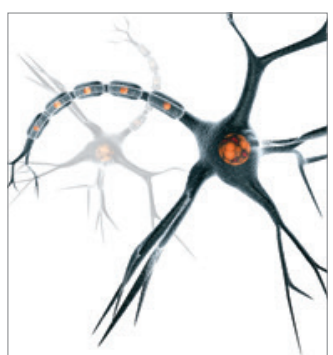

Neural Plasticity
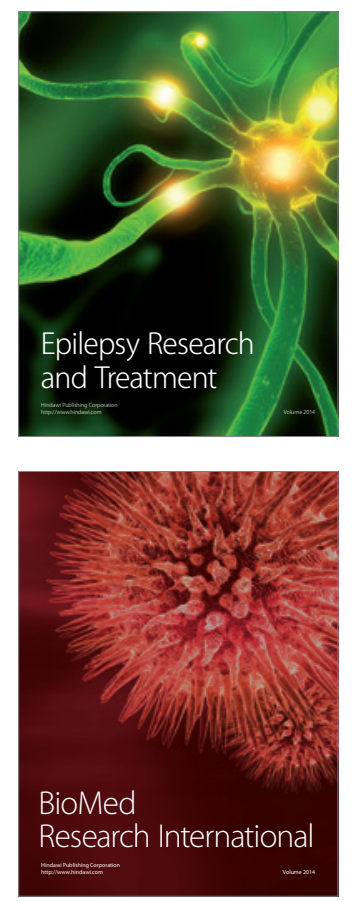

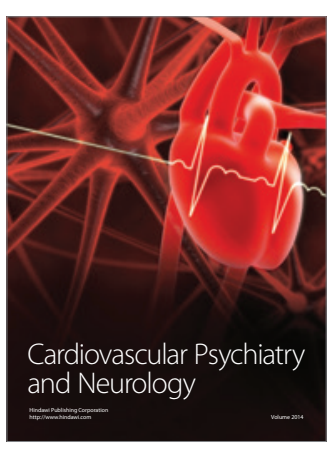

Parkinson's

Disease
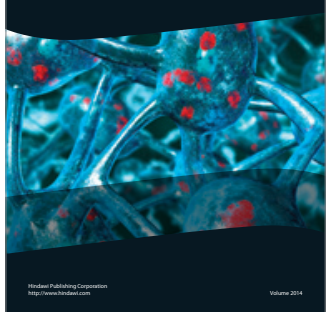